\title{
Fabrication of LPG Sensors Based upon Chemically Tailored Sizes of Chromium Oxide Nanoparticles \\ Nipin Kohli ${ }^{1}$, Onkar Singh ${ }^{1}$, Manmeet Pal Singh ${ }^{2}$, Ravi Chand Singh ${ }^{1}$ \\ ${ }^{1}$ Department of Physics, Guru Nanak Dev University, Amritsar 143005, India \\ nipinkohli82@yahoo.com \\ ${ }^{2}$ Department of Applied Sciences, Khalsa College of Engineering \& Technology, Amritsar-143001, India
}

\begin{abstract}
:
In this work, an attempt has been made to alter the particle size of chromium oxide and then to investigate sensing behaviour of these $\mathrm{Cr}_{2} \mathrm{O}_{3}$ samples towards LPG. We have followed chemical route for synthesizing nanoparticles of chromium oxide. To tailor nanoparticles of chromium oxide, synthesis was carried out at various reaction temperatures namely, 5,27 and $65^{\circ} \mathrm{C}$. In order to understand the structure and morphology of synthesized materials; they were subjected to X-ray diffraction and field emission scanning electron microscope. The obtained results have endorsed our prejudice and we found that reaction temperature has played a pivotal role in tailoring particle sizes. Interestingly, we observed that $\mathrm{Cr}_{2} \mathrm{O}_{3}$ nanoparticles synthesized at $27^{\circ} \mathrm{C}$ were smaller as compared to those synthesized at 5 and $65^{\circ} \mathrm{C}$. Thick film gas sensors of thus-prepared $\mathrm{Cr}_{2} \mathrm{O}_{3}$ powders were obtained by depositing them on alumina substrates. These fabricated sensors were studied for their optimum operating temperatures for LPG and we found that all the sensors exhibited best response at $250^{\circ} \mathrm{C}$. The investigation revealed that sensing response of $\mathrm{Cr}_{2} \mathrm{O}_{3}$ nanoparticles synthesized at $27^{\circ} \mathrm{C}$ was exceptionally higher than that of $\mathrm{Cr}_{2} \mathrm{O}_{3}$ nanoparticles synthesized at 5 and $65^{\circ} \mathrm{C}$.
\end{abstract}

Key words: semiconducting, nanoparticles, sensors, LPG

\section{Introduction}

Semiconducting metal oxides have been attracting substantial interest of scientific fraternity because of their low cost, simple construction, small size and good sensing properties [1]. Chromium oxide is an interesting material and belongs to same family. It has been a widely studied material because of its wide range of applications [2-4].

In the recent past, nanoparticles have gained importance due to their unique optical, electrical, thermal and catalytic properties.

In the present study we have synthesized chromium oxide nanostructures by using chemical route. The size modification of $\mathrm{Cr}_{2} \mathrm{O}_{3}$ nanoparticles was carried out by varying the reaction temperature of precursor solution and hence its effect on sensor response towards liquefied petroleum gas (LPG) has been investigated.

\section{Experimental Details} Synthesis of nanostructured $\mathrm{Cr}_{2} \mathrm{O}_{3}$ by
precipitation method

For obtaining precipitate, we initiated with the 0.2 $\mathrm{M}$ solution of $\mathrm{CrCl}_{3} \cdot 6 \mathrm{H}_{2} \mathrm{O}$ in distilled water to which ammonia solution was added drop wise with continuous stirring. Following similar procedure, we prepared three different reaction mixtures and maintained their reaction temperature at 5,27 and $65^{\circ} \mathrm{C}$. The resulting precipitate in each case was separated from solutions, washed and dried at $120^{\circ} \mathrm{C}$, and samples thus collected were calcined at $500 \circ \mathrm{C}$ for 3 hours.

\section{Material characterization}

For crystal structure analysis, the prepared samples were characterized by powder X-ray 
diffraction (XRD) using $\mathrm{Cu} \mathrm{Ka}$ radiation with Shimadzu 7000 Diffractometer. Morphology of the samples was analyzed by the field emission scanning electron microscope (FESEM) with FEI Quanta 200F. Brunauer-Emmett-Teller (BET) analysis was carried out to investigate the specific surface area with Gemini (V) 2380.

Fabrication of thick film sensor and sensor testing set up

To fabricate thick film sensors, a paste was prepared by mixing a proper amount of calcined powder with distilled water. The thick film of paste was then painted onto an alumina substrate (12 $\mathrm{mm} \times 5 \mathrm{~mm}$ size) having gold electrical contacts $2 \mathrm{~mm}$ apart. No material as a binder was used since fine particles of chromium oxide were self binding very well. Using above procedure a batch of sensors based on powders synthesized at different reaction temperature were fabricated and cured at $350^{\circ} \mathrm{C}$ for $30 \mathrm{~min}$.

For studying the sensing characteristics, a simple home built apparatus was used which consists of a simple potentiometric arrangement, a test chamber of 40 liters volume in which a sample holder, a small temperature controlled (by dimmer stat \& thermocouple) oven and a mixing fan were installed. The fabricated sensor was placed in the test chamber oven at suitable temperature, and known quantity of gas species was injected into the test chamber. Variation of real time voltage signal across a resistance connected in series with sensor was monitored and recorded was recorded with an experimental set up consisting of Keithley Data Acquisition Module KUSB-3100 and a computer. All the sensors were tested following same procedure by varying temperature from 200 to $400^{\circ} \mathrm{C}$.

\section{Results and discussion}

\section{Structural analysis}

Fig. 1 represents the X-ray diffraction pattern of materials synthesized at various reaction temperatures. The peaks visible in the graphs are in well agreement with standard available data, and these depict the corundum structure of nanosized chromium oxide. The crystallite size of chromium oxide powder synthesized at 5, 27 and $65^{\circ} \mathrm{C}$ was found to be $42.6,20.5$ and 30.2 $\mathrm{nm}$ as determined by using Scherrer's formula.

Fig. 2(a)-(c) represents the FESEM images of the nanostructured $\mathrm{Cr}_{2} \mathrm{O}_{3}$ powders at various reaction temperatures. Some clusters and agglomeration are also seen in the pictures.

The values obtained for the BET surface area are $13.9135,29.3875$ and $26.803 \mathrm{~m}^{2} / \mathrm{g}$ for the nanoparticles synthesized at 5,27 and $65^{\circ} \mathrm{C}$ respectively.

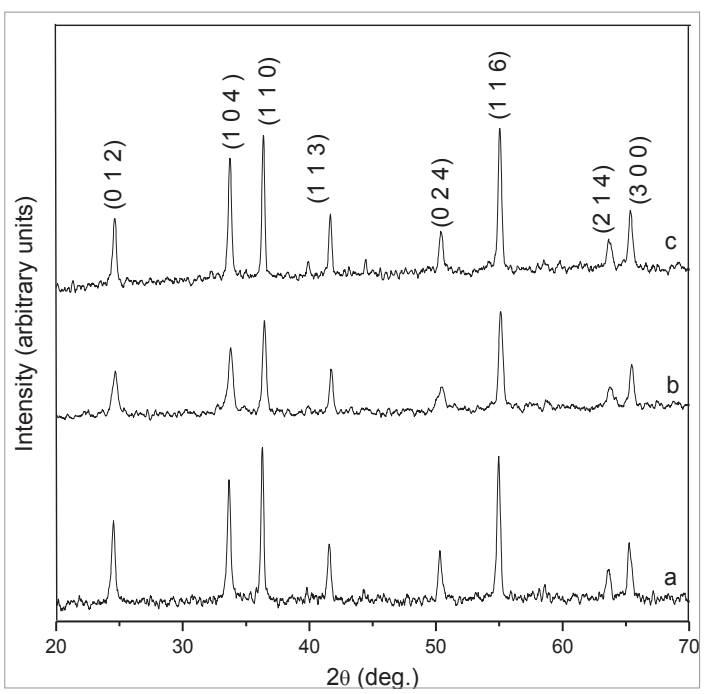

Fig. 1. XRD patterns of $\mathrm{Cr}_{2} \mathrm{O}_{3}$ powder synthesized at (a) $5^{\circ} \mathrm{C}$, (b) $27^{\circ} \mathrm{C}$ and (c) $65^{\circ} \mathrm{C}$.

Both hydrolysis and supersaturation are strongly dependent on reaction temperature. When the temperature is lowered from $27^{\circ}$ to $5^{\circ} \mathrm{C}$, slow hydrolysis reaction takes place which in turn leads to larger sized particles. Increase in temperature from $27^{\circ}$ to $65^{\circ} \mathrm{C}$ results in increased solubility and thus a reduced supersaturation of growth species in the solution. As a result, nuclei with small sizes may become unstable and dissolve back into the solution; dissolved species will then deposit onto the surfaces of large particles. This dissolutiongrowth process is also known as Ostwald ripening in which large particles grow at the expense of small particles [5].

\section{Sensing performance}

Sensors fabricated from powder synthesized at different reaction temperatures were exposed to $500 \mathrm{ppm}$ liquefied petroleum gas at different temperatures and results are shown in Fig. 3. Study revealed that optimum operating temperature of all the sensors remained invariant at $250^{\circ} \mathrm{C}$. 


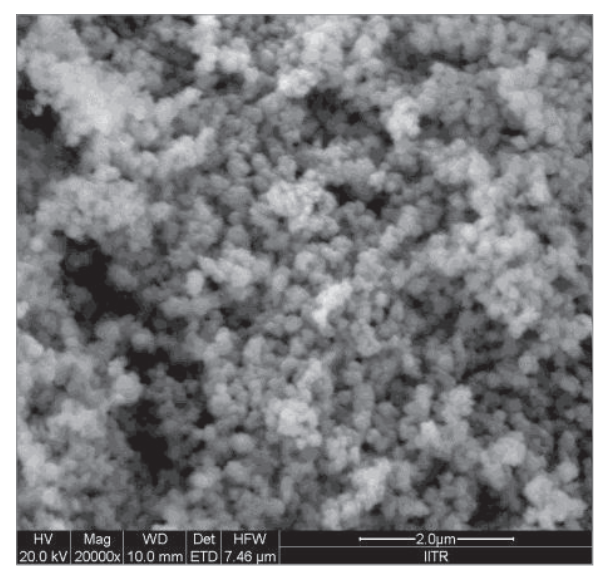

(a)

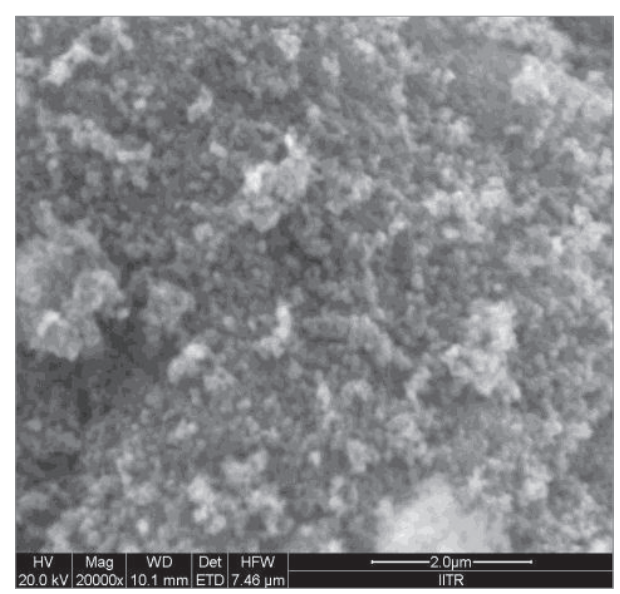

(b)

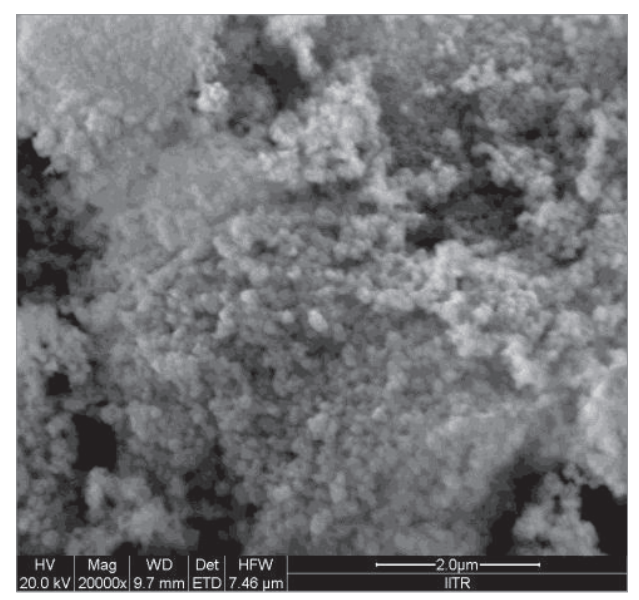

(c)

Fig. 2. FESEM micrographs of $\mathrm{Cr}_{2} \mathrm{O}_{3}$ powder synthesized at (a) $5^{\circ} \mathrm{C}$, (b) $27^{\circ} \mathrm{C}$ and (c) $65^{\circ} \mathrm{C}$.

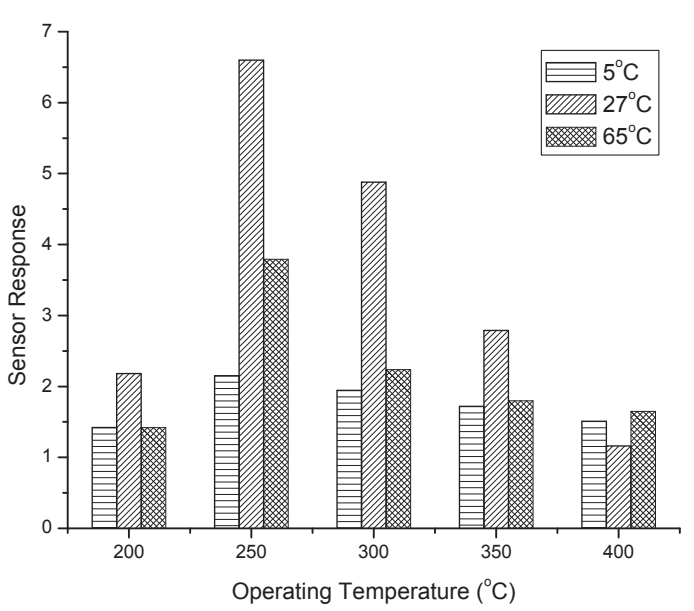

Fig.3. Sensing response of chromium oxide nanoparticles synthesized at 5,27 and $65^{\circ} \mathrm{C}$ towards 500 ppm of LPG at various operating temperatures.

It is also evident from the same figure that sensing response is exceptionally higher for the sample synthesized at $27^{\circ} \mathrm{C}$ as compared to samples synthesized at other reaction temperatures $\left(5\right.$ and $\left.65^{\circ} \mathrm{C}\right)$. The sensors fabricated from powder synthesized at $\mathrm{pH} 11$ were exposed to $500 \mathrm{ppm} \mathrm{LPG}$ at $250^{\circ} \mathrm{C}$ and the variation of sensor response with time is given in Fig. 4. Exceptionally higher sensing response of samples synthesized at temperature $27^{\circ} \mathrm{C}$ may be attributed to the smaller grain size obtained at this temperature. Another reason for enhanced sensing response of nanoparticles synthesized at $27^{\circ} \mathrm{C}$ is the larger effective surface area of smaller sized nanoparticles. Also a large number of small particles can be accommodated on a unit surface area contributing to large number of active sites onto which gaseous species adsorb to initiate sensing process.

When $\mathrm{Cr}_{2} \mathrm{O}_{3}$ based nanostructured sensors are exposed to air, oxygen molecules get adsorbed on the surface of the materials to form $\mathrm{O}_{2}^{-}, \mathrm{O}^{-}$, $\mathrm{O}^{2-}$ ions by capturing electrons, thereby removing holes from the valence band. As a result, conductance of sensors decreases. The reaction kinetics is given in eqs.(1-3).

$$
\begin{aligned}
& \mathrm{O}_{2} \text { (gas) } \leftrightarrow \mathrm{O}_{2} \text { (ads) } \\
& \mathrm{O}_{2} \text { (ads) }+\mathrm{e}^{-} \leftrightarrow \mathrm{O}_{2}^{-} \text {(ads) } \\
& \mathrm{O}_{2}^{-} \text {(ads) }+\mathrm{e}^{-} \leftrightarrow 2 \mathrm{O}^{-} \text {(ads) }
\end{aligned}
$$

When reducing gas such as LPG is injected into the test chamber, it reacts with the adsorbed 
oxygen resulting in the decrease in conductance. Therefore with reducing gas on this p-type sensor, the conductivity drops. Upon removal of reducing species or introduction of air or oxygen, the mechanism is reversed and the conductivity returns to its original state.

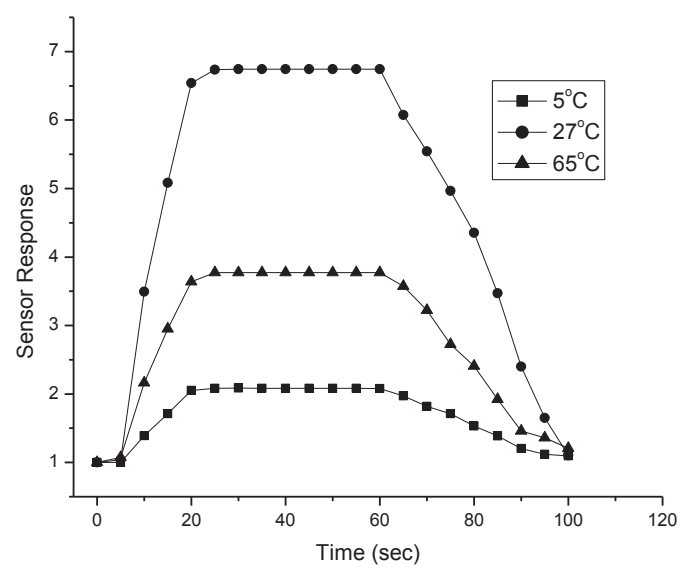

Fig. 4. Sensing characteristics of sensors fabricated from material synthesized at 5,27 and $65^{\circ} \mathrm{C}$ exposed to $500 \mathrm{ppm} L P G$ at $250^{\circ} \mathrm{C}$.

\section{Conclusions}

Chromium oxide nanoparticles have been synthesized using precipitation technique at different reaction temperatures. It was found that reaction temperature has played a pivotal role in tailoring particle sizes. Interestingly, we observed that $\mathrm{Cr}_{2} \mathrm{O}_{3}$ nanoparticles synthesized at $27^{\circ} \mathrm{C}$ were smaller as compared to those synthesized at 5 and $65^{\circ} \mathrm{C}$. Sensing response of synthesized powders was investigated for LPG and it was observed that sensor fabricated from powder synthesized at $27^{\circ} \mathrm{C}$ shows best response due to small crystallite size.

\section{Acknowledgements}

Authors would like to thank the following: University Grants Commission, New Delhi for financial support; SAIF, All India Institute of Medical Sciences, New Delhi for TEM investigations; Dr. S. A. Hashmi, Department of Physics and Astrophysics, University of Delhi for BET investigations.

\section{References}

[1] S. R. Morrison, Mechanism of semiconductor gas sensor operation, Sensors and Actuators B 11, 283-287 (1987); doi: 10.1016/0250874(87)80007-0

[2] Y. Takeda, R. Kanno, Y. Tsuji, O. Yamamoto, H. Taguch, Chromium oxides as cathodes for lithium cells, Journal of Power Sources 9, 325-328 (1983); doi: 10.1016/03787753(83)87034-7

[3] D.N. Suryawanshi, D.R. Patil, L.A. Patil, $\mathrm{Fe}_{2} \mathrm{O}_{3}$-activated $\mathrm{Cr}_{2} \mathrm{O}_{3}$ thick films as temperature dependent gas sensors, Sensors and Actuators B 134, 579-584 (2008); doi: 10.1016/j.snb.2008.05.045

[4] Y. Liu, D.Y. Chen, Protective coatings for $\mathrm{Cr}_{2} \mathrm{O}_{3}$-forming interconnects of solid oxide fuel cells, International Journal of Hydrogen Energy 34, 1-7 (2009); doi: 10.1016/j.ijhydene.2009.09.022

[5] G. Cao, Nanostructures and Nanomaterials: Synthesis, Properties \& Applications 1st ed., Imperial College Press, London. 